\title{
Carrier and Freight Forwarders Strategies to Utilize the Immobile Shipping Capacity of Freight Forwarders and Maximize Profits
}

\author{
Budisantoso Wirjodirdjo ${ }^{1 *}$, Akhmad Ghiffary Budianto ${ }^{1}$, Alain Widjanarka², \\ I Nyoman Pujawan ${ }^{1}$, Iffan Maflahah ${ }^{1}$ \\ ${ }^{1}$ Department of Industrial and System Engineering, Faculty of Industrial Technology and System \\ Engineering, Institut Teknologi Sepuluh Nopember, Kampus ITS Sukolilo, Surabaya 60111, Indonesia \\ ${ }^{2}$ Department of Operation Management, School of Management PPM, Menteng, Jakarta 10340, Indonesia
}

\begin{abstract}
Carriers and freight forwarders (FFs) play several roles in ensuring the effective flow of goods delivery. They are tasked with accommodating the shippers' needs in transporting goods via containers, following the carrier's ship destination plan. In practice, FFs often experience overbook and underbook capacity toward the capacity limit for shipping goods. This has consequently increased FF costs. However, for the carrier, this will increase profits. The aim of this study is to develop strategies for carriers and FFs using a mathematical model approach to obtain the optimal quantity of booking shipping capacity; thus, overbooks or underbooks can be minimized. More broadly, this study also proposes several strategies to increase the profits of all parties, both for FFs through collaboration and for carriers by directly selling marketing shipping capacity to shippers. Optimum booking quantity for goods delivery from each FF is performed through the particle swarm optimization (PSO) approach. Using four FF collaboration scenarios, the model test results yield a profit of $\$ 121,270,2.14 \%$ more than the non-collaboration scenarios with a profit of $\$ 119,169$. The carrier generated an average profit of $\$ 39,926$ when the FF did not collaborate. Conversely, when the FFs collaborated, the carrier experienced a decline of $-1.88 \%$ on average profit, which was $\$ 39,175$. However, if the carrier responds with direct selling, the profit will increase by $9.36 \%$, which is $\$ 42,840$. It is concluded that collaboration can increase the profits of FFs but reduce the profits of carriers, while direct selling can increase the carrier's profits.
\end{abstract}

Keywords: Average profit; Carrier; Collaboration; Direct sell; Freight forwarder

\section{Introduction}

Carriers and freight forwarders (FFs) are part of third-party logistics (3PL) in the freight forwarding business. Their role is to accommodate the shipper's needs in carrying out shipments of goods using containers and following planned demand necessities. As the owner of the shipping capacity of the container ship, the carrier is obligated to deliver the container goods following the shipper's request. An FF acts as the party that ensures the availability of this capacity in container ships and sells it to the shipper (Gupta, 2008). As a 3PL, the advantages of the carrier and FF depend on how much they can fulfill the shippers' demands in one delivery period. FFs obtain profit from the difference in the value of the

\footnotetext{
*Corresponding author's email: budisantoso.wirjodirdjo@gmail.com, Tel.: +62-81-8671305; Fax.: +62-315939362
}

doi: 10.14716/ijtech.v12i4.4413 
shipping capacity managed to be sold to the shipper against the capacity's purchased price by the FF from the carrier, following the booking contract of the capacity utilization. The FF will benefit if the booking contract capacities are entirely sold to the shipper. Conversely, the FF will experience losses if the booking contract capacities are not all sold to the shipper. The contract capacity held by the FF, which was not sold to the shipper, and the capacity owned by the carrier, which was not sold to the FF, will be forfeited after the ship is dispatched as a newsvendor's inventory (Widjanarka et al., 2018).

The FF makes various attempts to minimize losses caused by mismatching the number of goods delivery demands by the shipper against the total booking contract capacity reserved by the FF. Likewise, a carrier strives to fully utilize all the available shipping capacity on its ship. However, the demands for shipping capacity orders by shippers for FFs and the booking contract capacity demands from FFs to carriers are strongly influenced by the uncertainty of the business environment (Hellermann, 2006). In addition, operational problems often occur in the field related to the cancelation of shipping requests, late arrival of goods, or sudden shipping requests (Styhre, 2010).

So far, there have been many studies related to optimizing shipping capacity contracts by FFs to minimize the risk of over-or under-booking capacity for goods delivery. Gupta, in his research, proposed a flexible quantity of capacity booking contracts (Gupta, 2008). Thus, the amount of booking capacity in the next period can be adjusted by referring to the realization of capacity fulfillment that was reserved in the previous period. Meanwhile, Wang and Kao (2008) recommended that FFs need to minimize the risk of goods not being transported due to a lack of booked capacity. However, this does not rule out the possibility of excess booking capacity due to shippers' low demand for goods deliveries. In contrast, Bing and Bhatnagar (2013) proposed a model of capacity booking to be divided into several periods of the goods delivery. Likewise, another study introduced two capacity procurement patterns based on booking and non-booking capacity (Moussawi-Haidar, 2014). Approaching departure time, the carrier applies direct capacity sales with a first-infirst serve system. This pattern is intended to anticipate an increase in the demand for goods delivery. Research related to air freight proposed a package route for FFs shipping goods by air. The package is intended to utilize the shipping capacity owned by the carrier when there is a low demand for goods delivery (Feng et al., 2015).

The above stated research is from the perspective of the FF as an independent entity toward its relationship with the carrier and shipper. Another study followed another perspective and examined the cooperation among FFs and the relationships between carriers and shippers to balance the shipping demand and the availability of the shipping capacity for the FF's side (Kopfer and Pankratz, 1999). Krajewska and Kopfer (2006) reinforced this by developing a collaboration model among FFs that is expected to benefit both parties. Furthermore, a demand collaboration model related to planning more efficient routes of goods delivery was formulated (Krajewska et al., 2008). In contrast, Bookbinder et al. (2015) proposed a freight consolidation model to minimize the effective load for transportation. In another study, forwarders competed in ordering container capacity on a carrier's vessel. It was found that competition in these activities could benefit all parties, but carriers have the advantage of determining reservation rates where this will be the forwarder's excess burden cost (Li and Zhang, 2015). Finally, another study proposed a horizontal coalition model between FFs to reduce the cost of booking capacity for idle goods (Widjanarka et al., 2018).

From the ongoing discussions, there is a limitation to booking capacity models, capacity utilization, and the possibility of developing booking capacity models through horizontal coalitions among FFs. In addition, these studies have limitations regarding the available 
amount of capacity booked by FFs for carriers and the assumptions of the total number of booking capacity contracts that have a fixed economic value. Also, studies considering the perspectives of FFs and carriers remain scarce. Meanwhile, only Lin et al. (2017) proposed a booking capacity model for air cargo by adding negotiations to return excess capacity to the carrier (Lin et al., 2017). The latest research about FFs is related to omnichannel. It is a term used in Lafkihi et al. (2019) study to be broader than a multichannel (online and offline). They defined the omnichannel as a multichannel delivery with a high fluctuation and demand speed; thus, it is complex to consolidate traditional freight organizations. Therefore, coordinating shipping companies, FFs and carriers to maintain a high-demand speed is imperative.

This study has two main objectives: first, to develop a model that allows mitigation of overbook and underbook capacity problems by forming a horizontal collaboration among FFs. Second, the development of an alternative direct-selling business model made possible by carriers to shippers on the unsold shipping capacity to FFs. The achievement of these two goals is expected to provide an overview of the advantages and perspectives from both sides of the 3PL business actors in shipping containers through maritime transportation modes.

\section{Methods}

\subsection{Problem Description}

The process of booking shipping capacity by the FF begins with the carrier announcing the available capacities offered and the rate of reserving them per container unit. Based on the estimated needs, the FF will then book a certain capacity to the carrier and sell the shipping capacity to the shipper at a certain rate. There will be two possibilities after the FF fulfills the shipper's demand regarding the required container capacity. First, the condition of underbook capacity where the capacity booked by $\mathrm{FF}\left(\mathrm{q}_{\mathrm{n}}\right)$ is smaller than the demand from the shipper $\left(D_{n}\right)$, so FF needs to increase capacity by paying extra tariffs to the carrier to meet the demand. Second, the overbook capacity condition where the capacity booked by FF $\left(q_{n}\right)$ exceeds the demand from the shipper $\left(D_{n}\right)$, then FF will lose the booking fee because the booked capacity is not used (Widjanarka et al., 2018). With both the possibilities of underbook capacity and overbook capacity, as shown above, a model is proposed that can overcome both conditions to increase profit for all FFs. This can be achieved by establishing a coalition by offering booked capacity from FF with an overbook condition to FF with an underbook condition (Widjanarka et al., 2018). Sharing capacity is illustrated in Figure 1.

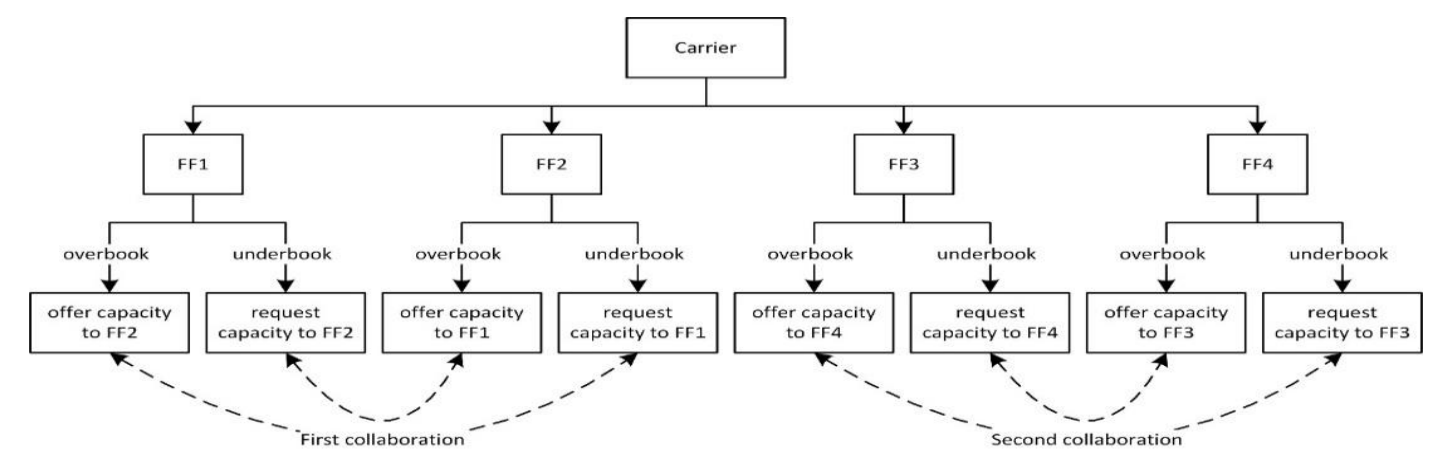

Figure 1 Sharing capacity optimization from the FF viewpoint

With the development of information technology that has been transfused to port operators and 3PL operational activities such as tracking container locations, checking 
container temperatures using wireless equipment system or even checking the power consumption of refrigerated containers (Budiyanto and Shinoda, 2017). Carriers can use the application or their own website to sell the remaining shipping capacity directly to the shippers after fulfilling the capacity demand booked from FF. However, consumers who are the main market share for carriers are still FF. Therefore, the sale of this capacity can only be done after the carrier has fulfilled all the capacity booked by FF. The carrier conveys this strategy to maximize the utilization of the carrier vessel's capacity. This can encourage the emergence of a new variable in the rates of direct capacity sales to shippers $(\theta)$. A condition that needs to be reconsidered is the direct sales rate to the shipper $(\theta)$ must be slightly more expensive than the capacity sales rate to $\mathrm{FF}\left(\mathrm{r}_{\mathrm{n}}\right)$ or $\theta>\mathrm{r}_{\mathrm{n}}$ in order to avoid business conflicts and to maintain the 3PL business sustainability. Figure 2 shows a schematic illustration of a direct capacity sale by a carrier to a shipper.

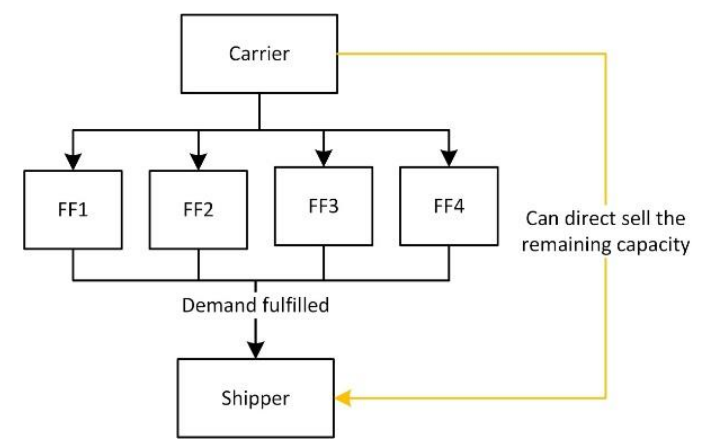

Figure 2 Conditions for direct sale to shippers

\subsection{Mathematical Formulation}

\subsubsection{The model of non-collaboration scenario between FF and carrier}

The methodology based on the problems discussed in the previous section, the problem regarding overbook and underbook capacity, can be modeled mathematically. Therefore, the profit of each FF is modeled as follows:

$$
Z F F_{n}=\left[\left(R_{n}-r_{0}\right) \operatorname{Min}\left(q_{n}, D_{n}\right)-\alpha r_{0}\left[D_{n}-q_{n}\right]^{+}-\beta r_{0}\left[q_{n}-D_{n}\right]^{+}\right]
$$

where

$$
\left[D_{n}-q_{n}\right]^{+}=\left\{\begin{array}{l}
D_{n}-q_{n} j i k a\left(D_{n}-q_{n}\right)>0 \\
0 \quad \text { jika }\left(D_{n}-q_{n}\right) \leq 0
\end{array}\right.
$$

The condition of underbook capacity is as follows:

$$
\left[q_{n}-D_{n}\right]^{+}=\left\{\begin{array}{rr}
q_{n}-D_{n} j i k a\left(q_{n}-D_{n}\right)>0 \\
0 \quad \text { jika }\left(q_{n}-D_{n}\right) \leq 0
\end{array}\right.
$$

To consider the condition of overbook capacity, the advantages of the carrier are modeled as follows:

$$
\begin{aligned}
Z_{c}= & {\left[\sum_{n}\left(r_{n}-p_{c}\right) \min \left(q_{n}, D_{n}\right)+\sum_{n} \alpha r_{n} \max \left(\left(D_{n}-q_{n}\right), 0\right)+\sum_{n} \beta r_{n} \max \left(\left(q_{n}-\right.\right.\right.} \\
& \left.\left.\left.D_{n}\right), 0\right)-p_{c} \max \left(\left(Q-\sum_{n} D_{n}\right), 0\right)\right]
\end{aligned}
$$


Table 1 Notations of the mathematical model

\begin{tabular}{cl}
\hline Notations & \\
\hline$Z F F_{n}$ & Potential profit for the FF with $\mathrm{n}$ as an identity $(\mathrm{n}=1,2,3,4)(\$)$ \\
$Z_{c}$ & Potential profit for the carrier $(\$)$ \\
$D_{n}$ & Shipping demands towards FF $\mathrm{n}(\mathrm{n}=1,2,3,4)$ (TEUs) \\
$p_{c}$ & Cost of capacity ownership $(\$ / \mathrm{TEUs})$ \\
$r_{n}$ & Capacity rate from carrier to FF $\mathrm{n}(\mathrm{n}=1,2,3,4)(\$ / \mathrm{TEU})$ \\
$R_{n}$ & Shipping rate from FF $\mathrm{n}$ fulfilling shipping demands $(\$ / \mathrm{TEUs})$ \\
$q_{n}$ & Total capacity booked by FF $\mathrm{n}(\mathrm{n}=1,2,3,4)$ to carrier $(\mathrm{TEU})$ \\
$q s_{m, n}$ & Total sharing capacity from FF $\mathrm{m}$ to FF $\mathrm{n}(\mathrm{m} \neq \mathrm{n})(\mathrm{TEUs})$ \\
$\mathrm{Q}$ & Amount of available carrier vessel's capacities (TEUs) \\
$\beta$ & Percentage of capacity booking fee charged by the carrier \\
$\alpha$ & Percentage increase of capacity rates due to additional capacity \\
\hline
\end{tabular}

\subsubsection{The model of the collaboration scenario between FFs}

Meanwhile, the solution regarding collaboration among FFs to optimize the conditions of the overbook and underbook capacity, which has been illustrated in Figure 1, is as follows:

$$
\begin{aligned}
Z F F_{n}= & {\left[\left(R_{n}-r_{0}\right) \operatorname{Min}\left(q_{n}+q s_{m, n}, D_{n}\right)-\alpha r_{0}\left[D_{n}-\left(q_{n}+q s_{m, n}\right)\right]^{+}-\beta r_{0}\left[\left(q_{n}+\right.\right.\right.} \\
& \left.\left.\left.q s_{m, n}\right)-D_{n}\right]^{+}\right]
\end{aligned}
$$

where

$$
q s_{m, n}=\left\{\begin{array}{cc}
q s_{m, n} & \text { if }\left(q_{n}-D_{n}\right)>0 \\
0 & \text { if }\left(q_{n}-D_{n}\right) \leq 0
\end{array}\right.
$$

$q s_{m, n}>0$ indicates an excess capacity in the $\mathrm{m}^{- \text {th }} \mathrm{FF}$ who is ready to do capacity sharing with other FFs. Therefore, the capacity sharing that occurs is as follows:

$$
\begin{gathered}
{\left[D_{n}-\left(q_{n}+q s_{m, n}\right)\right]^{+}=\left\{\begin{array}{rr}
D_{n}-\left(q_{n}+q s_{m, n}\right) & \text { if }\left(D_{n}-\left(q_{n}+q s_{m, n}\right)>0\right. \\
0 & \text { if }\left(D_{n}-\left(q_{n}+q s_{m, n}\right) \leq 0\right.
\end{array}\right.} \\
{\left[\left(q_{n}+q s_{m, n}\right)-D_{n}\right]^{+}=\left\{\begin{array}{cc}
q_{n}-D_{n} \text { if }\left(\left(q_{n}+q s_{m, n}\right)-D_{n}\right)>0 \\
0 & \text { if }\left(\left(q_{n}+q s_{m, n}\right)-D_{n}\right) \leq 0
\end{array}\right.}
\end{gathered}
$$

\subsubsection{The model of carrier strategies to directly sell the capacity}

Modeling the profits regarding the carrier if performing direct selling in the illustration in Figure 2 is as follows:

$$
\begin{aligned}
& Z_{c}=\left[\sum_{n=1,2}\left(r_{n}-p_{c}\right) \min \left(q_{n}, D_{n}\right)+\theta\left[\sum_{n} D_{n}+D_{s}-Q\right]^{+}+\sum_{n} \alpha r_{n} \max \left(\left(D_{n}-\right.\right.\right. \\
& \left.\left.\left.q_{n}\right), 0\right)+\sum_{n} \beta r_{n} \max \left(\left(q_{n}-D_{n}\right), 0\right)-p_{c} \max \left(\left(Q-\sum D_{n}-D_{s}\right), 0\right)\right]
\end{aligned}
$$

where

$$
\left[\sum_{n} D_{n}+D_{s}-Q\right]^{+}= \begin{cases}0 & \text { if }\left(\sum_{n} D_{n}+D_{s}-Q\right)>0 \\ \sum_{n} D_{n}+D_{s}-Q & \text { if }\left(\sum_{n} D_{n}+D_{s}-Q\right) \leq 0\end{cases}
$$

To increase profits by performing direct selling to shippers, the carrier must first prioritize meeting the demands of all FFs. Hence, there will be no excessive competition among 3PL actors when the rates for direct selling to shippers $(\theta)>$ rates from carrier to FF $\left(r_{n}\right)$. 


\subsection{Particle Swarm Optimization (PSO)}

This segment will explain the parts and stages of using the PSO algorithm approach used in this research. PSO simulates flocking behaviors. A group of birds is called a particle, where all the particles perform a search in space called fitness evaluation. In their motion, these particles have different velocities, so they will result in various fitness states. Therefore, in metaheuristic optimization, PSO is generally used as an optimization algorithm to combine production and capacity planning. This algorithm is quite easy to apply in various problem areas. Baskoro et al. (2011) used PSO to optimize the brightness range to detect the molten pool edge and compare it with the results of the Genetic Algorithm (GA). Both optimizations generate good results, although PSO is able to achieve minimum error faster than GA. Zhang et al. (2015) used PSO to optimize the combination of steel production capacity planning. Hannan et al. (2018) uses PSO as an optimization approach in transportation planning and scheduling related to the Capacitated Vehicle Routing Problem (CVRP). Summakieh et al. (2019) uses PSO to perform dynamic user associations by finding the optimal bias values. The resulting scheme achieves better load balancing performance in terms of the balance network index for Long Term EvolutionAdvanced (LTE-A) networks. In addition, PSO is also used in optimizing the design of container terminal capacity (Zukhruf et al., 2020). Figure 3 shows the PSO approach to find the optimal combination booking capacity solution in this study.

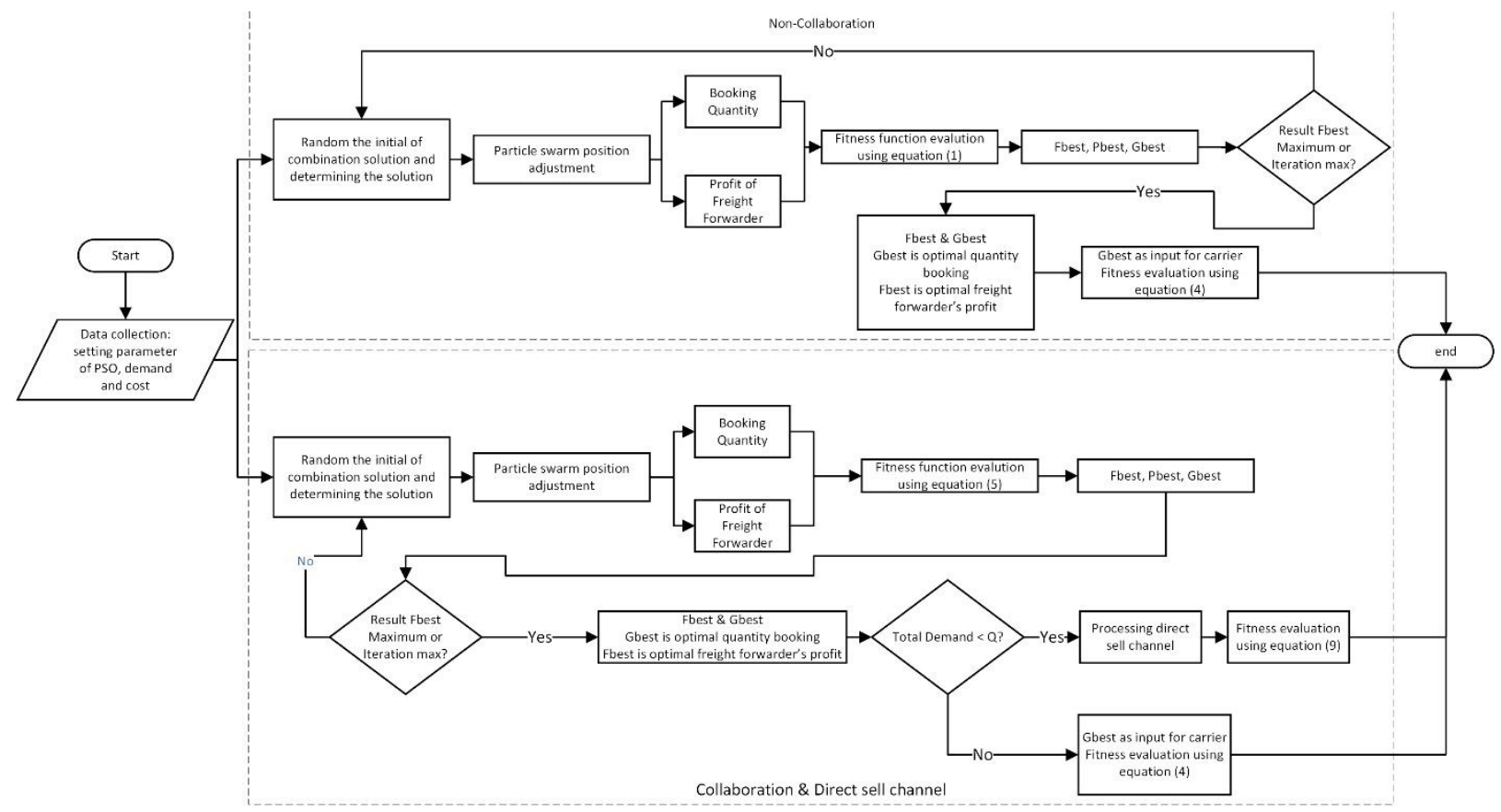

Figure 3 Flow chart of the PSO algorithm for solving the combination of booking capacity problems

Gbest will be an alternative solution for booking capacity in each iteration, while Fbest will be an alternative solution for FF profits. In this study, two types of stopping criteria are used. In the first stopping criterion, the iteration will be stopped if the number of the standard deviations of Gbest is below 1 (sum(std.dev(Gbest)) $<1$ ). In the second stopping criterion, the maximum iteration is set on the parameter used. In the FF collaboration scenario, direct sales will be made only if the carrier has fulfilled the demand from all FFs.

\section{Results and Discussion}

Previous research, specifically on collaboration between FFs and businesses in maritime transportation, has stated that the ordering capacity between forwarders and 
carriers benefits both sides. Krajewska et al. (2008), who developed a horizontal collaboration model among FFs, proved that horizontal collaboration can reduce the burden of forwarders and allocate profits efficiently. Also, Li and Zhang (2015) proposed a mathematical model called the capacity reservation model. The experimental results showed that competitive forwarders can benefit all sides with a notable statement of the additional capacity reservation price charged by the carrier to forwarders. However, this negatively impacts the forwarders. In another study, horizontal FF collaboration was shown to reduce overbook and underbook conditions that negatively impact FFs. This will increase the collaborating forwarders' profits but will reduce operator profits (Widjanarka et al., 2018). This research discusses the collaboration between FFs and carrier and carrier strategies in reducing the negative impact of horizontal collaboration among FFs.

\subsection{Numerical Analysis}

The mathematical model in the previous sub-chapter was tested with 1,000 demand data, assuming that the demand is normally distributed. Table 2 shows the patterns of demand and parameters for each FF.

Table 2 Demand pattern of each FF

\begin{tabular}{cccccccc}
\hline FF No. & Distribution & Mean & Std.dev & $\alpha(\%)$ & $\beta(\%)$ & $\mathrm{R}(\$)$ & $\mathrm{r}(\$)$ \\
\hline 1 & Normal & 200 & 60 & & & 1,000 & 700 \\
2 & Normal & 175 & 85 & \multirow{2}{*}{0.5} & 0.3 & 1,020 & 700 \\
3 & Normal & 150 & 70 & & & 1,050 & 765 \\
4 & Normal & 135 & 90 & & & 1,080 & 745 \\
\hline
\end{tabular}

Demands for direct sales are also tested using 1,000 demands with a normal distribution $(10,15)$. Based on the type of ship and its size, a feeder ship is a type of ship not designed for inter-ocean shipping. However, these types of vessels are commonly used in container shipping. These vessels have capacities up to several hundred TEUs (Eyres and Bruce, 2012). Capacity availability based on a single origin-destination route is more widely used, considering that ports in Indonesia have a limited average depth of only about 11 meters or range between 6 and 13 meters (Sadjiono et al., 2018). With existing port technical specifications, the container ships that dock in Indonesia are around 1,000 TEUs. So, we used 1,000 TEUs as the maximum capacity of carrier vessel (Q), the rate for direct selling capacity to shipper $(\theta)$ is set at $\$ 790$, and the cost of capacity ownership (pc) is set at $\$ 500$. Meanwhile, the parameters used in the PSO algorithm are as follows: $\mathrm{N}$ is set to 10 particles,

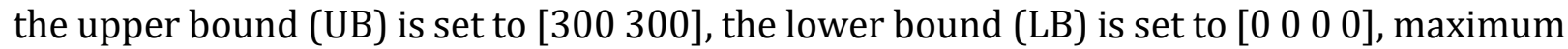
iteration is 100 , rho $(\rho)$ is set to $0.5, C 1$ and $C 2$ are 1 . All the data and parameters were used in the numerical analysis using MATLAB R2018 as computational software.

\subsection{Result and Analysis for Non-Collaborative and Collaborative Scenarios}

Assessing a non-collaborative mathematical model between FFs with the PSO algorithm produces an optimal order quantity for FF\#1 totaling 238 TEUs with an average profit of $\$ 43,396, \mathrm{FF} \# 2$ totaling 236 TEUs with an average profit of $\$ 33,912, \mathrm{FF} \# 3$ totaling 197 TEUs with an average profit of $\$ 23,204$, and FF\#4 totaling 200 TEUs with an average profit of $\$ 18,657$. Figure 4 shows the variable changes with the PSO algorithm toward each iteration. 

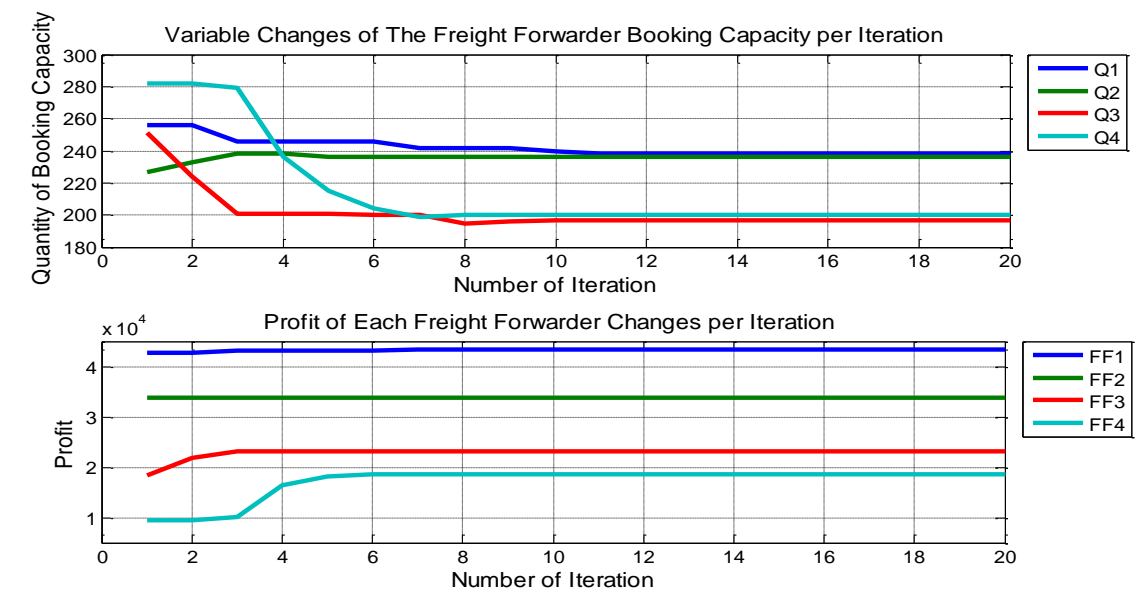

Figure 4 Variation in booking quantity and profit of FF per iteration

Figures 5 and 6 show the outcomes of analyzing a collaborative mathematical model between FFs using the same parameter inputs. Based on the test results using the PSO algorithm, the order quantity for FF\# 1 totals 218 TEUs with an average profit of $\$ 44,900$, FF\#2 totals 195 TEUs with an average profit of \$34,381, FF\#3 totals 184 TEUs with an average profit of $\$ 24,960$, and FF\#4 totals 241 TEUs with an average profit of $\$ 17,241$. So the total collaboration profit of FFs is $\$ 121,720$.

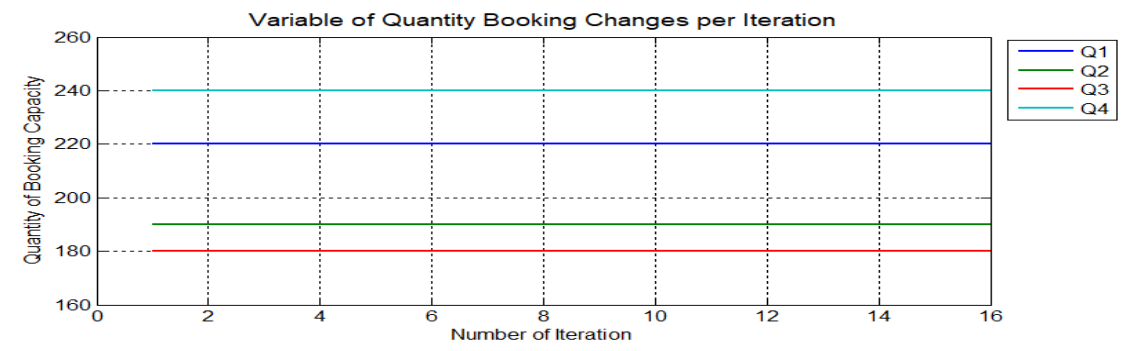

Figure 5 The quantity booking of the collaboration model among FFs

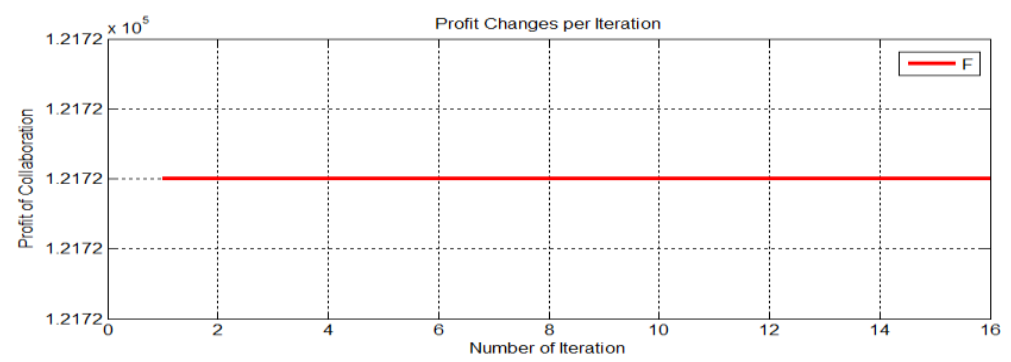

Figure 6 The quantity booking and profit of the collaboration model among FFs

Once the results of testing from collaboration and non-collaboration scenarios are established, based on this comparison through the results of the collaboration scenario, there was an increase in the number of orders from FF\#4, which was originally 200 TEUs for non-collaboration. However, by not collaborating, it increased to 241 TEUs. Meanwhile, there was a decrease in booking capacity of FF\#1, FF\#2, and FF\#3, which were originally non-collaboration, and 238, 236, and 197 TEUs, with collaboration, respectively, dropping to 218,195 , and 184 TEUs. Thus, the decrease in total capacity from non-collaboration, which was originally 870 TEUs to 838 TEUs, was due to capacity sharing between FFs. 
Figure 7 presents a comparison of the outcomes of the collaboration and non-collaboration scenarios among FFs.

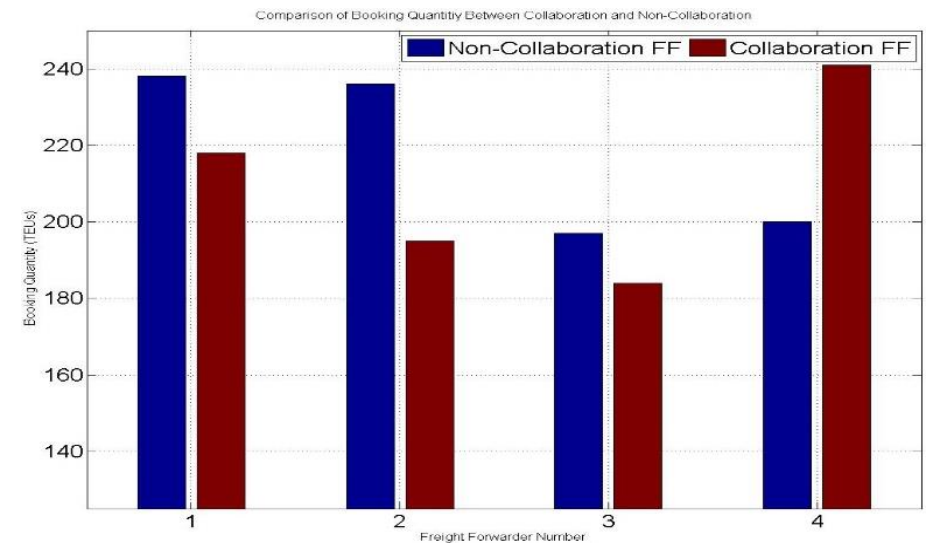

Figure 7 Comparison of booking capacities of each FF

After reviewing the differences in booking quantity caused by the collaboration and non-collaboration scenarios, this section will also examine the benefits of FFs and carriers by collaboration and non-collaboration. Based on the trial results, the FF collaboration scenario yielded an average profit of $\$ 121,720$. This profit increased by $2.14 \%$, which, from the original non-collaboration scenario, resulted in an average profit of $\$ 119,169$. The increase in profits was due to the cost savings from overbooks and underbooks and capacity sharing from the collaboration among FFs. Meanwhile, the carrier collaboration scenario resulted in an average profit of $\$ 39,175$. This profit decreased by $-1.88 \%$ from the original, with the non-collaboration scenario generating an average profit of $\$ 39,926$. This also impacts optimizing the capacity sharing of the collaboration scenario so that carrier revenue regarding addition or subtraction in ordering capacity is reduced. Figure 8 presents a comparison of the average profit between the collaboration and noncollaboration scenarios of FFs and carriers.

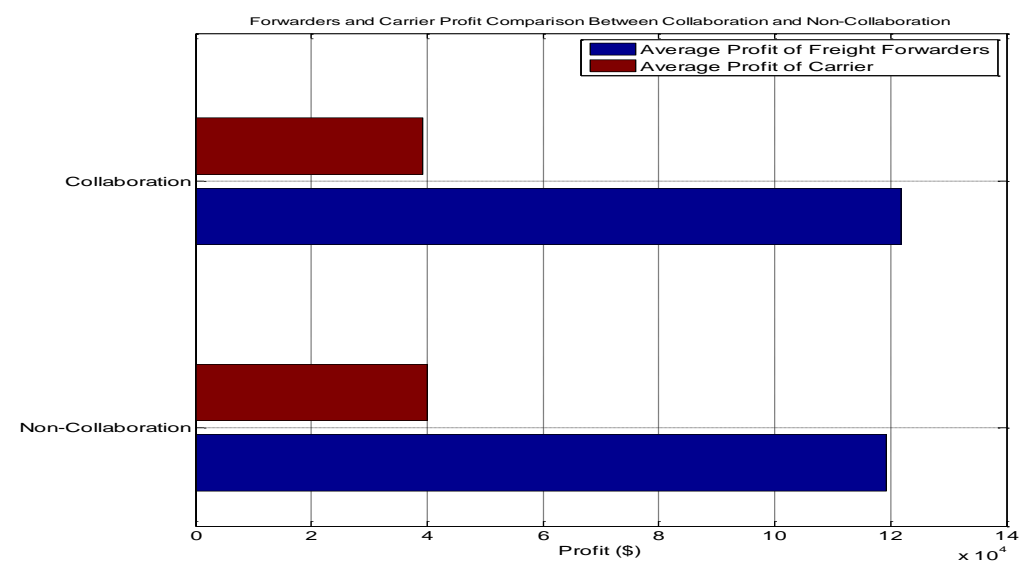

Figure 8 Comparison of the average profit per scenario between forwarders and carriers

\subsection{Result and Analysis for Direct Sell Capacity Scenario}

Based on the trial outcomes of the average carrier profit that meets the demands of all FFs and direct selling, the profit increases up to $\$ 42,840$. This is an increase in profits of $9.36 \%$ from the average carrier profit under the collaboration scenario totaling $\$ 39,175$, whereas in the non-collaboration scenario, the average carrier profit of $\$ 39,926$ decreases 
by $-1.88 \%$ to $\$ 39,175$ in the collaboration scenario. Figure 9 shows a comparison of the average profit in each carrier scenario.

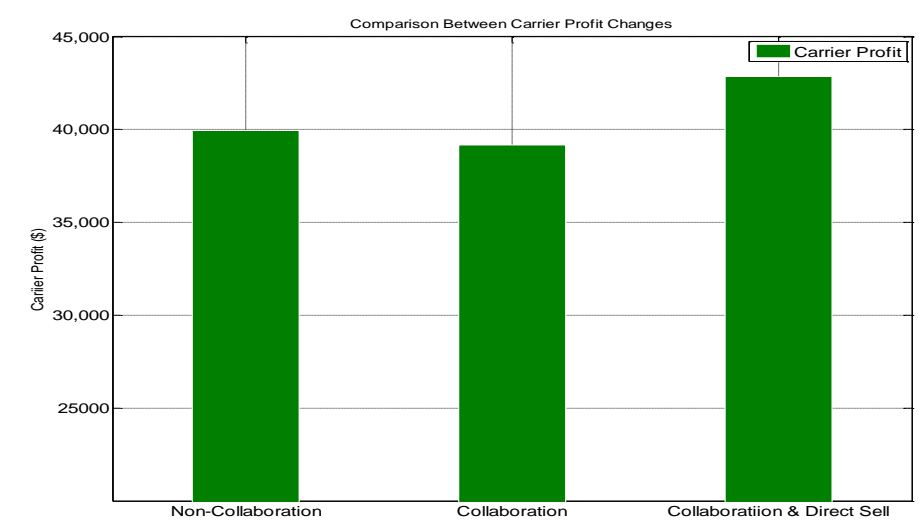

Figure 9 Comparison of the average carrier profit in each scenario

\section{Conclusions}

Based on the numerical experiment results, the increase in profit of the collaboration scenario occurs due to the optimization of capacity sharing performed by each collaborating FF to reduce overbook and underbook capacity. However, from the carrier's viewpoint, the collaboration strategy among FFs decreases the average profit. This is because a new sales channel has emerged as a direct sales channel to reduce carrier losses with the growth and development of information technology. By implementing a direct sales channel strategy, the carrier can increase profits according to the amount of direct sales demand that can be fulfilled in a given period. This can reduce the capital burden on the carrier when the number of demands is less than half of the carrier vessel's total capacity.

\section{Acknowledgements}

The authors wish to extend gratitude to: first, PT. Pelindo III, as a corporate state, for permitting its corporation to be chosen as an object in this research. Second, the Ministry of Education and Culture Republic of Indonesia (Kemendikbud) granted research funding, the contract number : 1262/PKS/ITS/2020. Finally, Institut Teknologi Sepuluh Nopember, Surabaya, permitted its resources and facilities to be used to conduct the research.

\section{References}

Baskoro, A.S., Masuda, R., Suga, Y., 2011. Comparison of Particle Swarm Optimization and Genetic Algorithm for Molten Pool Detection in Fixed Aluminum Pipe Welding. International Journal of Technology, Volume 2(1), pp. 74-83

Bing, L., Bhatnagar, R., 2013. Optimal Capacity Booking in Air Cargo Transportation. Journal of Revenue and Pricing Management, Volume 12(3), pp. 235-253

Bookbinder, J.H., Elhedhli, S., Li, Z., 2015. The Air-Cargo Consolidation Problem with Pivot Weight: Models and Solution Methods. Computers \& Operations Research, Volume 59, pp. 22-32

Budiyanto, M.A., Shinoda, T., 2017. Stack Effect on Power Consumption of Refrigerated Containers in Storage Yards. International Journal of Technology, Volume 8(7), pp. 1182-1190

Eyres, D.J., Bruce, G.J., 2012. Ship Dimensions, Form, Size, or Category. Ship Construction, $7^{\text {th }}$ Edition, Elsevier, pp. 11-16 
Feng, B., Li, Y., Shen, H., 2015. Tying Mechanism for Airlines' Air Cargo Capacity Allocation. European Journal of Operational Research, Volume 244(1), pp. 322-330

Gupta, D., 2008. Flexible Carrier-Forwarder Contracts for Air Cargo Business. Journal of Revenue and Pricing Management, Volume 7(4), pp. 341-356

Hannan, M.A., Akhtar, M., Begum, R.A., Basri, H., Hussain, A., Scavino, E., 2018. Capacitated Vehicle-Routing Problem Model for Scheduled Solid Waste Collection and Route Optimization using PSO Algorithm. Waste Management, Volume 71, pp. 31-41

Hellermann, R., 2006. Capacity Options for Revenue Management: Theory and Applications in The Air Cargo Industry, Volume 575. Springer Science \& Business Media

Kopfer, H., Pankratz, G., 1999. Das Groupage-Problem Kooperierender Verkehrsträger. In: Operations Research Proceedings 1998, pp. 453-462

Krajewska, M.A., Kopfer, H., 2006. Collaborating Freight Forwarding Enterprises. OR Spectrum, Volume 28(3), pp. 301-317

Krajewska, M.A., Kopfer, H., Laporte, G., Ropke, S., Zaccour, G., 2008. Horizontal Cooperation Among Freight Carriers: Request Allocation and Profit Sharing. Journal of the Operational Research Society, Volume 59(11), pp. 1483-1491

Lafkihi, M., Pan, S., Ballot, E., 2019. Freight Transportation Service Procurement: A Literature Review and Future Research Opportunities in Omnichannel E-Commerce. Transportation Research Part E: Logistics and Transportation Review, Volume 125, pp. 348-365

Li, L., Zhang, R.Q., 2015. Cooperation Through Capacity Sharing Between Competing Forwarders. Transportation Research Part E: Logistics and Transportation Review, Volume 75, pp. 115-131

Lin, D., Lee, C.K.M., Yang, J., 2017. Air Cargo Revenue Management Under Buy-Back Policy. Journal of Air Transport Management, Volume 61, pp. 53-63

Moussawi-Haidar, L., 2014. Optimal Solution for a Cargo Revenue Management Problem with Allotment and Spot Arrivals. Transportation Research Part E: Logistics and Transportation Review, Volume 72, pp. 173-191

Sadjiono, I., Istijab, B., Malisan, J., 2018. A Potential Freight Consolidation Center for Asia Pacific Regional Hub: An Importance Performance Analysis. Jurnal Penelitian Transportasi Laut, Volume 20, pp. 98-108

Styhre, L., 2010. Capacity Utilisation in Short Sea Shipping. Chalmers University of Technology. Ph.D. Thesis. Göteborg, Sweden

Summakieh, M.A., Tan, C.K., El-Saleh, A.A., Chuah, T.C., 2019. Improved Load Balancing for Lte-A Heterogeneous Networks using Particle Swarm Optimization. International Journal of Technology, Volume 10(7), pp. 1407-1415

Wang, Y.-J., Kao, C.-S., 2008. An Application of A Fuzzy Knowledge System for Air Cargo Overbooking Under Uncertain Capacity. Computers \& Mathematics with Applications, Volume 56(10), pp. 2666-2675

Widjanarka, A., Wirjodirdjo, B., Pujawan, I.N., Baihaqi, I., 2018. Coalition in Utilization Capacity in Container Transportation Services. International Journal of Applied Science and Engineering, Volume 15(2), pp. 95-104

Zhang, T., Zheng, Q.P., Fang, Y., Zhang, Y., 2015. Multi-Level Inventory Matching and Order Planning Under The Hybrid Make-To-Order/Make-To-Stock Production Environment for Steel Plants Via Particle Swarm Optimization. Computers \& Industrial Engineering, Volume 87, pp. 238-249

Zukhruf, F., Widhiarso, W., Frazila, R.B., 2020. A Comparative Study on Swarm-based Algorithms to Solve the Stochastic Optimization Problem in Container Terminal Design. International Journal of Technology, Volume 11(2), pp. 374-387 